\title{
Unexpected oocyte growth after follicular antrum formation in four marsupial species
}

\author{
J. C. Rodger ${ }^{1,2}$, I. Giles ${ }^{1}$ and K. E. Mate ${ }^{1}$ \\ ${ }^{1}$ Department of Biological Sciences, University of Newcastle, NSW, Australia; and ${ }^{2}$ Department of \\ Genetics, Southwest Foundation for Biomedical Research, San Antonio, Texas, USA
}

\begin{abstract}
Summary. During examination of maturing preovulatory marsupial oocytes we noted that oocyte diameters were invariably about $50 \%$ greater than the figures reported in earlier histological studies. As all previous investigations were limited to small follicles (at most $25 \%$ the size of the ovulating follicle), the present study was initiated to examine oocyte growth during the whole period of follicular development. Oocyte and follicle diameters were measured for three Australian (Trichosurus vulpecula, Macropus eugenii and Bettongia penicillata - fresh nonfixed material) and one American marsupial species (Monodelphis domestica - histological sections) in which multiple follicle development had been induced by exogenous gonadotrophin treatment. In all species oocytes were obtained from follicles ranging from pre-antral to immediately pre-ovulatory (maximum follicle sizes obtained were: $T$. vulpecula, $4.5 \mathrm{~mm}$; $M$. eugenii, $4.3 \mathrm{~mm}$; . penicillata, $2.5 \mathrm{~mm} ; M$. domestica, $0.7 \mathrm{~mm}$ ). In two of the species ( $T$. vulpecula and $B$. penicillata) ovulated oocytes were also examined.

In T. vulpecula and $M$. eugenii oocytes were found to achieve much greater diameters than previously reported from histological studies of small follicles $(<0.8 \mathrm{~mm})$ and similar patterns of growth were found in the other two species. In the four species oocytes reached diameters about two to three times that found for eutherian mammals. It was concluded that the marsupial oocyte continued to grow after formation of the follicular antrum and that, although the rate of oocyte growth slowed in larger follicles, it continued into the period immediately before ovulation. In $B$. penicillata the largest oocytes were obtained after ovulation. The increases in diameter corresponded to a three to four times increase in the volume of oocytes from follicular antrum formation to ovulation.

These data, and our earlier observations on cortical granule formation, suggest that the marsupial oocyte operates on a very different developmental timetable from the eutherian oocyte. The most likely basis of the observed late growth is the accumulation of 'yolk'.
\end{abstract}

Keywords: oocyte growth; antral Graafian follicles; marsupial; common brushtail possum; tammar wallaby; brush-tailed bettong; opossum; Monodelphis

\section{Introduction}

It has been accepted for some time that oocyte and follicle growth is biphasic in eutherian mammals (reviews Brambell, 1956; Peters \& McNatty, 1980; Wassarman, 1988). During the pre-antral stage of follicular development (phase A), both the oocyte and follicle grow concurrently until the oocyte has reached its maximum diameter. The period that follows (phase B) consists of follicular growth alone. In phase $B$, the follicle expands through an increase in granulosa cell layers and the formation of a fluid-filled cavity, the antrum. An essentially similar pattern of oocyte and follicle growth has been reported for all marsupials examined. 
Alcorn (1975) confirmed the basic biphasic pattern of marsupial oocyte growth in a study of the development of the tammar wallaby ovary. He concluded that the major phase of oocyte growth ceased just prior to antrum formation. Lintern-Moore et al. (1976) and Lintern-Moore \& Moore (1977) undertook a broad survey and reported that all nine of the marsupial species they examined exhibited a similar biphasic pattern of oocyte and follicle growth and that oocyte growth ceased at about the time of antrum formation. Both found that oocyte growth could be represented as two regression lines intersecting at the point in follicular growth where the antrum was first seen. It was suggested that the only difference between the eutherian and marsupial follicular growth pattern was the maximum diameter attained by the follicle and oocyte at the end of phase A.

A later study (Panyaniti et al., 1985), which examined oocyte numbers and growth in the ovaries of immature, adult and hypophysectomized tammar wallabies (Macropus eugenii), confirmed the general pattern found by these earlier workers. However, they concluded that the data better fitted an exponential curve with its inflection at the point of follicular antrum formation. All these studies were based on measurements of oocytes and follicles in sections of ovaries processed through Bouin's fixative and conventional paraffin histology.

In the course of studies of maturing preovulatory oocytes of brushtail possums (Trichosurus vulpecula) treated with a superovulatory regimen (Rodger \& Mate, 1988), we noted that oocyte diameters were invariably about $50 \%$ greater than the figures reported in earlier histological studies. All the earlier data came from ovaries apparently not selected for any particular phase of the oestrous cycle and was limited to follicles that were less than $25 \%$ the diameter of the ovulatory follicle. In the Australian species examined in most detail very few large preovulatory follicles would ever be found as they are present for only a few days in a month long cycle and only one follicle grows to ovulatory size. The advent of a superovulation technique for marsupials means that we now have access to far greater numbers of large follicles than the earlier workers and the present study was initiated to examine oocyte growth during the whole of follicular development and after ovulation.

\section{Materials and Methods}

\section{Animals}

Common brushtail possums (Trichosurus vulpecula) were live-trapped in the Newcastle region. Tammar wallabies (Macropus eugenii) and brush-tailed bettongs (Bettongia penicillata) were obtained from the breeding colonies at the CSIRO Division of Wildlife and Ecology, Canberra. All animals were housed at the University of Newcastle Central Animal House under conditions described previously (Rodger \& Mate, 1988; Mate \& Rodger, 1991; Mate et al., 1992). Grey short-tailed opossums (Monodelphis domestica) were from the colony at the Southwest Foundation for Biomedical Research, San Antonio, Texas. Their care and breeding was as described by Fadem et al. (1982).

\section{Superovulation}

The ovaries were stimulated using a two-stage pregnant mares' serum gonadotrophin (PMSG)/gonadotrophinreleasing hormone $(\mathrm{GnRH})$ treatment based on the protocol developed for the brushtail possum (Rodger \& Mate, 1988). This involved an initial injection of PMSG (Folligon: Intervet, Oss, The Netherlands) followed 3 days later by single or multiple intramuscular injections of synthetic GnRH (Fertagyl: Intervet, Australia) or human luteinizinghormone-releasing hormone (LHRH) (Sigma L-7134: Sigma Chemical Co., St Louis, Missouri). Ovulation was expected about $24 \mathrm{~h}$ after GnRH stimulation in the possum and bettong (Rodger \& Mate, 1988; Hayman et al., 1990) and $48 \mathrm{~h}$ after LHRH in the wallaby and opossum (Rodger et al., in press; K. E. Mate, E. S. Robinson, J. L. Van de Berg \& J. C. Rodger, unpublished).

Detailed doses and timing were as follows: brushtail possum (preovulatory $n=5$; ovulated $n=4$ ); day 0 : 10 iu PMSG s.c.; day 3: $3 \times 50 \mu \mathrm{g}$ GnRH i.m. at $90 \mathrm{~min}$ intervals. Tammar wallaby $(n=12)$; day 0: 10 iu PMSG i.m.; day 3: $3 \times 30 \mu \mathrm{g}$ LHRH i.m. (in $0 \cdot 2 \mathrm{ml}$ olive oil) at $3 \mathrm{~h}$ intervals. Brush-tailed bettong (preovulatory $n=3$; ovulated $n=1$ ); day 0: 20 iu PMSG s.c.; day 3: $3 \times 50 \mu \mathrm{g} \mathrm{GnRH} \mathrm{i.m.} \mathrm{at} 90$ min intervals. Monodelphis $(n=6)$; day $0: 1$ iu PMSG s.c.; day 3: a single injection $20 \mu \mathrm{g}$ LHRH i.m. (in saline).

\section{Collection of ovaries and measurement of oocytes and follicles}

Before GnRH stimulation, ovaries were obtained by unilateral ovariectomy in the possum, wallaby and bettong. Anaesthesia was induced by $0.5 \mathrm{ml}$ i.m. injection of tiletamine chlorhydrate $\left(50 \mathrm{mg} \mathrm{ml}^{-1}\right)$ and zolazepam chlorhydrate 
( $50 \mathrm{mg} \mathrm{ml}^{-1}$ ) ('Zoletil 100': Virbac, Australia) and maintained throughout surgery by $2 \cdot 5 \%$ halothane ('Fluothane': ICI, Australia). The ovaries were surgically removed through a mid-line incision in the abdominal wall just above the pouch. Animals were killed 12-24 h after GnRH treatment by a single i.v. injection of barbiturate (Euthatal 350: May and Baker, Australia) at a dose rate of $50 \mathrm{mg} \mathrm{kg}^{-1}$ of body weight. The ovaries were removed (prior to expected ovulation) through a midline abdominal incision and placed in Hank's Balanced Salts Solution (HBSS).

Fresh preparations were used to obtain measurements of oocyte and follicle diameter for the possum, wallaby and bettong. Follicles were dissected from the ovaries and large follicles $(>0.5 \mathrm{~mm})$ measured using Vernier callipers. Small follicles were measured using a calibrated eye piece scale and a Zeiss IDO2 inverted microscope. Oocytes were released from their follicles by pricking with a 30 gauge needle and measured using the microscope eye piece scale. Ovulated oocytes were recovered by flushing the oviduct via its uterine end using a blunt needle and syringe. Heparin $\left(12.5 \mathrm{iu} \mathrm{ml}^{-1}\right)$ was included in the flushing medium (HBSS) as an anticoagulant. Oocyte diameters are those for the outer surface of the zona pellucida. The diameter of the vitellus was also measured. The vitelline diameter of possum oocytes was $7.4 \pm 0.68 \%$ (mean \pm SEM) smaller than the zona pellucida diameter and the wallaby $7 \cdot 7 \pm 0.24 \%$ and bettong $9 \cdot 0 \pm 0.45 \%$, respectively. The zona pellucida data were used in preference to the vitelline diameter because they were less affected by individual variability in shape and the zona pellucida gave a clearer image for measurement.

Opossums were killed by $\mathrm{CO}_{2}$ and their ovaries removed and placed in Bouin's fixative. Measurements of follicle and oocyte diameter were made on conventional wax histology slides stained with haematoxylin and eosin using a calibrated eye piece scale.

The diameter of follicles in which antrum formation was beginning was measured on Bouin's fixed histological sections of bettong and opossum ovaries using the eye piece scale as described above.

\section{Results}

In the four species examined oocyte growth was found to continue after follicular antrum formation. Antrum formation has been reported to occur in $0.22 \mathrm{~mm} T$. vulpecula and $0.20 \mathrm{~mm} M$. eugenii follicles (Lintern-Moore et al., 1976) and was found to occur in $0 \cdot 16 \mathrm{~mm} \mathrm{~B}$. penicillata and $0.17 \mathrm{~mm} M$. domestica follicles.

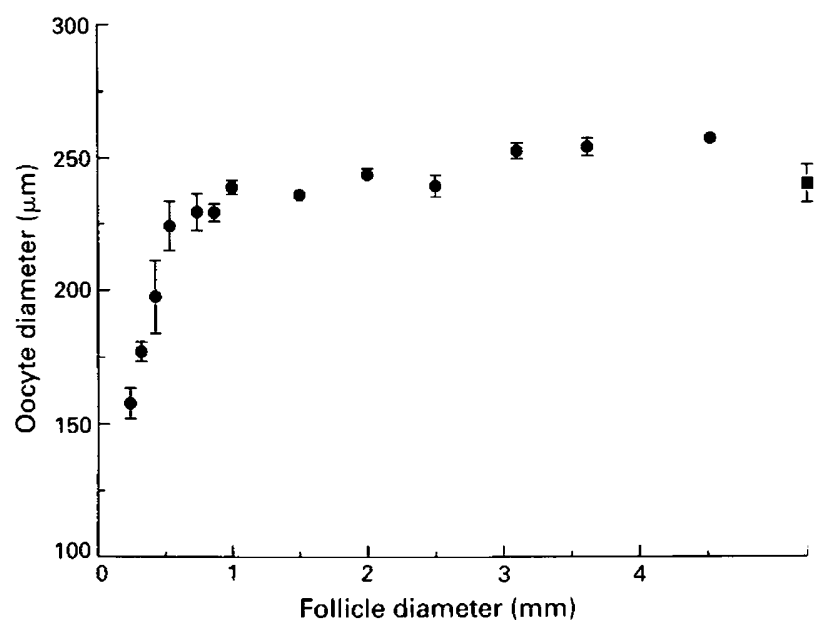

Fig. 1. Oocyte diameter (mean \pm SEM) of ovulated ova $(\boldsymbol{D})$ and follicular oocytes $(\boldsymbol{O})$ plotted against stage in follicular development, for the common brushtail possum Trichosurus vulpecula. Data obtained for 81 follicular and 26 ovulated oocytes is presented. Each data point is based on 3-13 observations. The follicle diameter for each data point is the average for that group of observations.

\section{Trichosurus vulpecula}

Oocyte diameter increased sharply from about $158 \mu \mathrm{m}$ in $0.24 \mathrm{~mm}$ follicles (antrum formation $0.22 \mathrm{~mm}$ follicles) to $240 \mu \mathrm{m}$ in $1.0 \mathrm{~mm}$ follicles (Fig. 1). This corresponds to a 3.5 -fold increase in 
oocyte volume. Although the rate of subsequent oocyte growth was much less marked, oocytes continued to increase in diameter as follicle size increased towards ovulation (Table 1). Preovulatory follicles $>2.5 \mathrm{~mm}$ in diameter contained the largest oocytes (maximum diameter $258 \mu \mathrm{m}$ in $4.5 \mathrm{~mm}$ follicles). The mean diameter of ovulated oocytes $(240 \mu \mathrm{m})$ was smaller than that found in the largest follicles and equal to that in the $1-2.5 \mathrm{~mm}$ follicles (Table 1). The diameters of ovulated oocytes were highly variable ranging from 155 to $393 \mu \mathrm{m}$. Ovulated oocytes were obtained $30 \mathrm{~h}(n=1)$ and $36 \mathrm{~h}(n=3)$ after the first GnRH injection. The oocytes collected at $30 \mathrm{~h}$ were found in the folds of the oviductal fimbria. Those collected at $36 \mathrm{~h}$ were all within the oviduct.

Table 1. Diameters of oocytes during the preovulatory period of follicular development and after ovulation for four marsupial species

\begin{tabular}{lccc}
\hline Species & $\begin{array}{c}\text { Follicular } \\
\text { stage }\end{array}$ & $\begin{array}{c}\text { Number of } \\
\text { oocytes }\end{array}$ & $\begin{array}{c}\text { Oocyte } \\
\text { diameter }\end{array}$ \\
\hline Trichosurus vulpecula & $1 \cdot 0-1 \cdot 5 \mathrm{~mm}$ & 20 & $237 \cdot 9 \pm 1 \cdot 87^{\mathrm{a}}$ \\
& $2 \cdot 0-2 \cdot 5 \mathrm{~mm}$ & 17 & $240 \cdot 4 \pm 3 \cdot 20^{\mathrm{a}}$ \\
& $2 \cdot 8-4 \cdot 6 \mathrm{~mm}$ & 14 & $254 \cdot 8 \pm 1 \cdot 70^{\mathrm{b}}$ \\
& Ovulated & 26 & $240 \cdot 3 \pm 7 \cdot 14^{\mathrm{a}}$ \\
Macropus eugenii & $1 \cdot 0-1 \cdot 5 \mathrm{~mm}$ & 77 & $175 \cdot 7 \pm 1 \cdot 46^{\mathrm{a} *}$ \\
& $2 \cdot 0-2 \cdot 5 \mathrm{~mm}$ & 46 & $180 \cdot 3 \pm 1 \cdot 79^{\mathrm{b}}$ \\
& $3 \cdot 0-5 \cdot 0 \mathrm{~mm}$ & 27 & $185 \cdot 0 \pm 3 \cdot 31^{\mathrm{b}}$ \\
& LHRH $+0 \mathrm{~h}$ & 28 & $158 \cdot 6 \pm 2 \cdot 34^{\mathrm{a}}$ \\
& LHRH $+12 \mathrm{~h}$ & 20 & $153 \cdot 9 \pm 3 \cdot 29^{\mathrm{a}}$ \\
& LHRH $+24 \mathrm{~h}$ & 102 & $183 \cdot 7 \pm 1 \cdot 29^{\mathrm{b}}$ \\
Bettongia penicillata & $1 \cdot 0 \mathrm{~mm}$ & 12 & $167 \cdot 4 \pm 2 \cdot 26^{\mathrm{a}}$ \\
& $1 \cdot 5-3 \cdot 0 \mathrm{~mm}$ & 6 & $168 \cdot 8 \pm 2 \cdot 89^{\mathrm{a}}$ \\
& Ovulated & 5 & $194 \cdot 6 \pm 1 \cdot 40^{\mathrm{b}}$ \\
Monodelphis domestica & $0 \cdot 28 \mathrm{~mm}$ & 4 & $150 \cdot 5 \pm 6 \cdot 34^{\mathrm{a}}$ \\
& $0 \cdot 53 \mathrm{~mm}$ & 5 & $172 \cdot 6 \pm 3 \cdot 56^{\mathrm{b}}$ \\
& $0 \cdot 58 \mathrm{~mm}$ & 6 & $168 \cdot 0 \pm 2 \cdot 23^{\mathrm{b} * *}$ \\
& $0 \cdot 63 \mathrm{~mm}$ & 5 & $176 \cdot 9 \pm 7 \cdot 47^{\mathrm{b}}$ \\
& $0 \cdot 67 \mathrm{~mm}$ & 3 & $190 \cdot 9 \pm 2 \cdot 43^{\mathrm{b} * *}$ \\
& &
\end{tabular}

Within each species, or data grouping, identical superscripts indicate that mean oocyte diameters are not significantly different from those immediately below or above. Where superscripts differ the data are significantly different by Student's $t$ test $P=0.001$ (except for ${ }^{*}(P=0.05)$ ). ${ }^{* *}$ Mean oocyte diameter in $0.67 \mathrm{~mm}$ follicles is significantly different from that in $0.58 \mathrm{~mm}$ follicles $(P=0.001)$. LHRH: luteinizing-hormone-releasing hormone.

\section{Macropus eugenii}

In $M$. eugenii oocytes underwent a similar pattern of growth to that seen in the ovary of the brushtail possum (Fig. 2). Oocyte diameter increased rapidly from $120 \mu \mathrm{m}$ in $0.23 \mathrm{~mm}$ follicles (antrum formation $0.20 \mathrm{~mm}$ follicles) to $180 \mu \mathrm{m}$ as follicle diameter rose to $1.5 \mathrm{~mm}$. Subsequently, the rate of growth slowed. Although the maximum mean oocyte diameter $(192 \mu \mathrm{m})$ was obtained in the $4.3 \mathrm{~mm}$ follicles (Fig. 2), there was no significant increase in oocyte size in follicles $>1.5 \mathrm{~mm}$ (Table 1). However, evidence of late preovulatory oocyte growth was seen when the data for follicles $1 \mathrm{~mm}$ or greater were analysed on the basis of time after LHRH treatment $(0,12$ or $24 \mathrm{~h}$; Table 1). Oocytes collected $24 \mathrm{~h}$ after LHRH were significantly larger. Oocyte growth from $120 \mu \mathrm{m}$ to $190 \mu \mathrm{m}$ diameter corresponded to a fourfold increase in oocyte volume. 


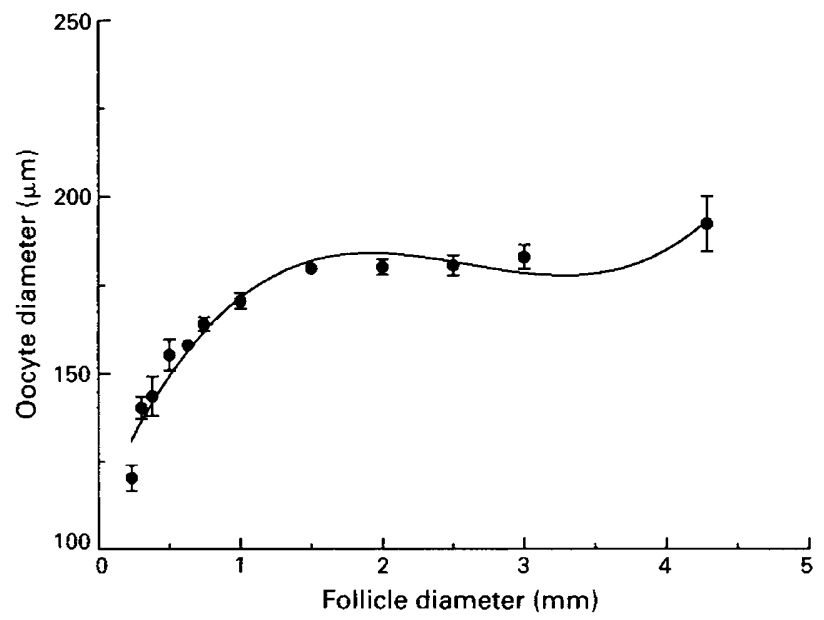

Fig. 2. Oocyte diameter (mean \pm SEM) plotted against follicle diameter for the tammar wallaby, Macropus eugenii. Data were obtained for 193 follicular oocytes. Each data point is based on 5-41 observations. The follicle diameter for each data point is the average for that group of observations. A third-order regression line has been fitted to the data $(r=0.99)$.

\section{Bettongia penicillata}

The bettong showed a similar pattern of oocyte growth to that seen in the previous two species (Fig. 3). A rapid phase of growth was seen from $120 \mu \mathrm{m}$ in $0.15 \mathrm{~mm}$ follicles (antrum formation $0.16 \mathrm{~mm}$ follicles) to $167 \mu \mathrm{m}$ in $1.0 \mathrm{~mm}$ follicles. The maximum oocyte diameter achieved was $170 \mu \mathrm{m}$ in $2.0 \mathrm{~mm}$ follicles but no preovulatory follicles contained oocytes significantly larger than those in $1.0 \mathrm{~mm}$ follicles. The largest oocytes were obtained after ovulation (mean diameter $194.6 \pm 1.40 \mu \mathrm{m}$, Table 1). The increase in oocyte diameter from $120 \mu \mathrm{m}$ to $190 \mu \mathrm{m}$ corresponded to a fourfold increase in volume. The ovulated oocytes were obtained from the uterus $43 \mathrm{~h}(n=1)$ after the first GnRH injection.

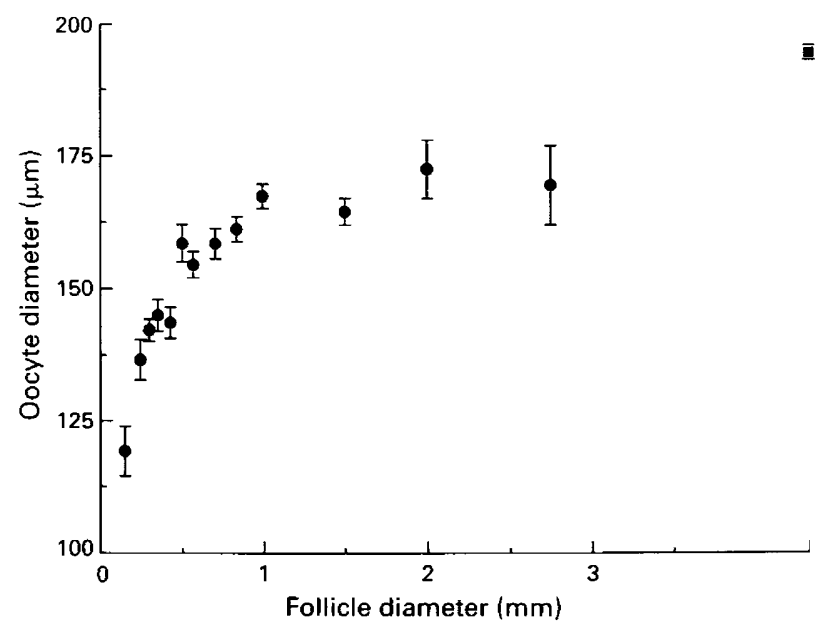

Fig. 3. Oocyte diameter (mean \pm SEM) of ovulated ova $(\square)$ and follicular oocytes $(\bullet)$ plotted against stage in follicular development, for the brush-tailed bettong, Bettongia penicillata. Data obtained for 91 follicular and 5 ovulated oocytes are presented. Each data point is based on 4-12 observations (except for $1.5,2.0$ and $2.5 \mathrm{~mm}$ follicles where $n=2$ ). The follicle diameter for each data point is the average for that group of observations. 


\section{Monodelphis domestica}

Initially oocyte diameter increased rapidly from $25 \mu \mathrm{m}$ in $0.03 \mathrm{~mm}$ follicles to $150 \mu \mathrm{m}$ in $0.28 \mathrm{~mm}$ follicles (Fig. 4). Subsequently oocytes maintained a more gradual increase in diameter (Table 1). Oocyte diameter was significantly greater in $0.53 \mathrm{~mm}$ follicles (mean diameter $173 \mu \mathrm{m}$ ). Through the next four follicle stages examined $(0.53-0.67 \mathrm{~mm})$ the increase in oocyte diameter was not significantly different at each step. However, the largest follicles $(0.67 \mathrm{~mm})$ contained the largest oocytes $(191 \mu \mathrm{m})$ and these were of significantly greater diameter than oocytes in follicles up to $0.58 \mathrm{~mm}$ diameter (Table 1). Antrum formation occurred in $0.17 \mathrm{~mm}$ follicles with oocytes of $128 \mu \mathrm{m}$ diameter. There was a 3.3-fold increase in oocyte volume as diameter rose from $128 \mu \mathrm{m}$ to $190 \mu \mathrm{m}$. Maximum preovulatory follicle diameter in $M$. domestica is $1.0 \mathrm{~mm}(\mathrm{~K}$. E. Mate, E. S. Robinson, J. L. Van de Berg \& J. C. Rodger, unpublished).

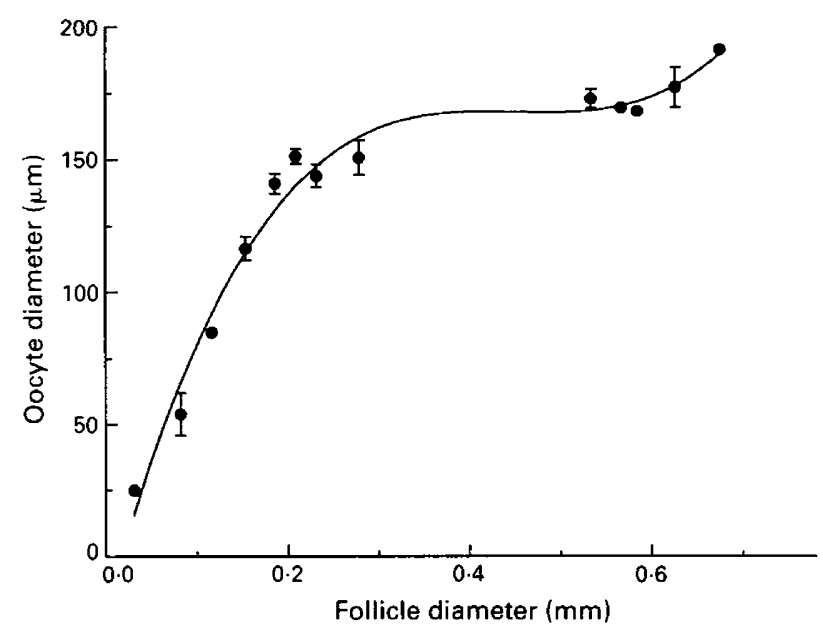

Fig. 4. Oocyte diameter (mean \pm SEM) plotted against follicle diameter for the grey short-tailed opossum, Monodelphis domestica. Data were obtained for 56 follicular oocytes. Each data point is based on 3-6 observations (except for $0.08 \mathrm{~mm}$ follicles where $n=2$ ). The follicle diameter for each data point is the average for that group of observations. A third-order regression line has been fitted to the data $(r=0.99)$.

\section{Discussion}

Oocyte follicular growth in marsupials has previously been shown to follow the biphasic pattern seen in eutherians (Alcorn, 1975; Lintern-Moore et al., 1976; Lintern-Moore \& Moore, 1977; Panyaniti et al., 1985). All studies concluded that the completion of oocyte growth coincided with, or just preceded, the onset of antrum formation. The present study indicated that phase A of the biphasic growth pattern reported by these authors only partially describes the growth of the marsupial oocyte.

In the four species examined, oocytes continued to increase in diameter after antrum formation and growth was even seen in the period immediately before ovulation. If the increased diameters from follicle antrum formation to maximum size were expressed as volumes, the increase was from 3.3 to 4.0 times. The maximum oocyte diameters for the possum and wallaby were greater and were recorded in much larger follicles than previously documented. Oocyte sizes were considerably larger than the maximum reported by Lintern-Moore \& Moore (1977) but of similar dimensions to published data for tubal ova (T. vulpecula, $241 \mu \mathrm{m}$, Hughes \& Hall, 1984; M. eugenii, $139 \mu \mathrm{m}$, 
Renfree \& Tyndale-Biscoe, 1978). Further, Hughes \& Hall (1984) found that oocytes in large preovulatory follicles had a diameter of $225 \mu \mathrm{m}$, intermediate between that for ovulated oocytes and the 'maximum' diameter of $170 \mu \mathrm{m}$ found in small follicles by Lintern-Moore and colleagues. A maximum oocyte diameter of $191 \mu \mathrm{m}$ was found in the opossum Monodelphis. However, this was from fixed material and immediately preovulatory follicles were not examined. The observations of Baggott et al. (1987) indicate that oocyte growth continues further in this species. They reported that the diameter of unfixed mature preovulatory oocytes (first polar body present) was $250 \mu \mathrm{m}$. The results from this study suggest that the difference in maximum oocyte diameter between eutherians and marsupials is greater than previously thought, owing to the extended period of oocyte growth in marsupials. The maximum diameter of the marsupial oocyte, about $190 \mu \mathrm{m}$ in wallaby and bettong and $250 \mu \mathrm{m}$ in the possum and opossum, is two to three times larger than the eutherian oocyte (range 56-108 $\mu \mathrm{m}$; Lintern-Moore \& Moore, 1977).

Very late preovulatory growth was demonstrated in three of the species studied. In the possum and opossum, this final oocyte growth appeared to be related to an increase in follicle diameter. In the tammar it was not linked to follicle diameter but followed the LHRH-induced LH surge. The data would suggest that although the rate of growth is not dramatic during the later phase of follicle life, it is significant and may continue until ovulation.

Ovulated oocytes in the bettong were larger than the largest follicular oocytes, suggesting that an undetected late preovulatory growth had occurred or that growth had continued after ovulation. In contrast, ovulated possum oocytes were found to be smaller $(5 \cdot 7 \%)$ than those in the largest follicles. It has previously been reported that marsupial oocytes may decrease in diameter after ovulation. Hartman (1919) and McCrady (1938) found in the Virginia opossum (Didelphis virginiana) that maximum preovulatory oocyte diameter was $150 \mu \mathrm{m}$ (average of largest and smallest diameters of the non-circular oocyte) and yet the diameter of the ovulated oocyte was 126 or $113 \mu \mathrm{m}$, respectively. It was suggested that the decrease in diameter may represent an osmotic effect, i.e. fluid loss.

Measurements taken from fixed preparations have been the conventional method for studying oocyte and follicular growth in marsupials. The present study mainly examined unfixed oocytes. This technique limited the collection of follicles to diameters greater than $0.2 \mathrm{~mm}$ but eradicated the problem of shrinkage and fixative effects on oocyte sizes. However, the large differences in oocyte diameter between this and earlier histological studies cannot be attributed to methodology. Evidence of the basic normality of superovulated oocytes is that most undergo nuclear maturation and that fertilization can follow natural mating (Rodger \& Mate, 1988; Rodger et al., 1992, in press). However, judging from the size range of ovulated possum oocytes $(155-393 \mu \mathrm{m})$, it is possible that gonadotrophin treatment may have induced ovulation of abnormally small oocytes or that oocytes may have been retained for longer in the ultimate growth phase prior to ovulation. Interestingly, a similar wide range in oocyte diameter has been noted at natural ovulation in the polyovulatory Monodelphis (K. E. Mate, E. S. Robinson, J. L. Van de Berg \& J. C. Rodger, unpublished).

This is the first study that has investigated marsupial oocyte growth in all stages of follicular development including pre- and post-ovulation. Our finding that the growth of the marsupial oocyte continues after follicle antrum formation and even into the immediately preovulatory period was quite unexpected. It suggests, together with our finding that cortical granules are formed very late in marsupials (Mate et al., 1992), that the marsupial oocyte operates on a very different developmental timetable to the eutherian oocyte. The basis of this previously undetected growth phase needs to be examined to establish its relevance to fertilization or embryonic development. The most likely explanation for this growth pattern is that the oocyte is laying down its store of yolk. Marsupial eggs contain a large amount of yolky material compared with eutherian eggs and have an unusual cleavage pattern. During first cleavage a large amount of cytoplasm (about one third) is separated from the embryo by formation of either an anuclear yolk mass (e.g. dasyurids, Selwood \& Smith, 1990) or a mass of cytoplasmic yolk bodies (Tyndale-Biscoe \& Renfree, 1987; Baggott \& Moore, 1990). Despite the many general references to the yolky character of marsupial 
eggs, the manner of yolk formation and its role in development has not been examined directly. Indeed the 'yolk' of mammalian eggs, which in the mouse may account for as much as $50 \%$ of the protein of the oocytes (Wassarman, 1988), is poorly understood. Since there is evidence that there can be dramatic changes in diameter between follicular and ovulated oocytes, it is also possible that some of the changes may reflect fluid accumulation or loss in the immediately pre- or post-ovulatory period and not synthetic activity per se.

We wish to acknowledge the major financial support of the Australian Research Council and minor support by the Research Management Committee of the University of Newcastle. The work of J. C. Rodger at the Southwest Foundation for Biomedical Research was supported in part by funding from that institution and in part by a grant from the Australian Department of Industry, Technology and Commerce's Science and Technology Collaboration Program. All animal experimentation was carried out under approved protocols of the Animal Care and Ethics Committees of the University of Newcastle and Southwest Foundation for Biomedical Research.

\section{References}

Alcorn, G.T. (1975) Development of the Ovary and Urinogenital Ducts in the Tammar Wallaby Macropus eugenii (Desmarest, 1817). PhD Thesis. Macquarie University, Sydney.

Baggott, L.M. \& Moore, H.D.M. (1990) Early embryonic development of the grey short-tailed opossum, Monodelphis domestica, in vivo and in vitro. Journal of Zoology 222, 623-639.

Baggott, L.M., Davis-Butler, S. \& Moore, H.D.M. (1987) Characterization of oestrus and timed collection of oocytes in the grey short-tailed opossum, Monodelphis domestica. Journal of Reproduction and Fertility 79, 105-114.

Brambell, F.W.R. (1956) Ovarian Changes. In Marshall's Physiology of Reproduction, Vol. 1, pp. 397-457. Ed. A. S. Parkes. Longmans, London.

Fadem, B.H., Trupin, G.L., Maliniak, E., VandeBerg, J.L. \& Hayssen, V. (1982) Care and breeding of the gray, short-tailed opossum (Monodelphis domestica). Laboratory Animal Science 32, 405-409.

Hartman, C.G. (1919) Studies in the development of the opossum Didelphis virginiana L. I. History of the early cleavage. II. Formation of the blastocyst. Journal of Morphology 27, 1-83.

Hayman, D.L., Smith, M.J. \& Rodger, J.C. (1990) A comparative study of chiasmata in male and female Bettongia penicillata (Marsupialia). Genetica 83, 45-49.

Hughes, R.L. \& Hall, L.S. (1984) Embryonic development in the common brushtail possum Trichosurus vulpecula. In Possums and Gliders, pp. 197-212. Eds A. P. Smith \& I. D. Hume. Surrey Beatty and Sons, Sydney.

Lintern-Moore, S. \& Moore, G.P.M. (1977) Comparative aspects of oocyte growth in mammals. In Reproduction and Evolution, pp. 215-219. Eds J. H. Calaby \& C. H. Tyndale-Biscoe. Australian Academy of Science, Canberra.

Lintern-Moore, S., Moore, G.P.M., Tyndale-Biscoe, C.H. \& Poole, W.E. (1976) Growth of oocyte and follicle in the ovaries of monotremes and marsupials. Anatomical Record 185, 325-332.
McCrady, E. (1938) The embryology of the opossum. American Anatomical Memoirs 16, 1-233.

Mate, K.E. \& Rodger, J.C. (1991) Stability of the acrosome of the brush-tailed possum (Trichosurus vulpecula) and tammar wallaby (Macropus eugenii) in vitro and after exposure to conditions and agents known to cause capacitation or acrosome reaction of eutherian spermatozoa. Journal of Reproduction and Fertility 91, 41-48.

Mate, K.E., Giles, I. \& Rodger, J.C. (1992) Evidence that cortical granule formation is a periovulatory event in marsupials. Journal of Reproduction and Fertility 95, 719-728.

Panyaniti, W., Carpenter, S.M. \& Tyndale-Biscoe, C.H. (1985) Effects of hypophysectomy on folliculogenesis in the tammar Macropus eugenii (Marsupialia: Macropodidae). Australian Journal of Zoology 33, 303-311.

Peters, H. \& McNatty, K.P. (1980) The Ovary: a Correlation of Structure and Function in Mammals. Granada Publishing, London.

Renfree, M.B. \& Tyndale-Biscoe, C.H. (1978) Manipulation of marsupial embryos and pouch young. In Methods in Mammalian Reproduction, pp. 307-331. Ed. J. C. Daniel. Academic Press, New York.

Rodger, J.C. \& Mate, K.E. (1988) A PMSG/GnRH method for the superovulation of the monovulatory brush-tailed possum (Trichosurus vulpecula). Journal of Reproduction and Fertility 83, 885-891.

Rodger, J.C., Breed, W.G. \& Bennett, J.H. (1992) Gonadotrophin-induced oestrus and ovulation in the polyovulatory marsupial Sminthopsis crassicaudata. Reproduction Fertility and Development 4, 145-152.

Rodger, J.C., Cousins, S.J., Mate, K.E. \& Hinds, L.A. Ovarian function and its manipulation in the tammar wallaby, Macropus eugenii. Reproduction Fertility and Development (in press).

Selwood, L. \& Smith, D. (1990) Time-lapse analysis and normal stages of development of cleavage and blastocyst formation in the marsupials the Brown Antechinus and the Stripe-faced Dunnart. Molecular Reproduction and Development 26, 53-62. 
Tyndale-Biscoe, C.H. \& Renfree, M. (1987) Reproductive Physiology of Marsupials. Cambridge University Press, Cambridge.
Wassarman, P.M. (1988) The Mammalian Ovum. In The Physiology of Reproduction, Vol. 1, pp. 69-102. Eds E. Knobil \& J. D. Neill. Raven Press, New York.

Received 14 November 1991 